\title{
Stock Market Volatility And Presidential Election Uncertainty: Evidence From Political Futures Markets
}

\author{
David R. Bowes, Southeastern Louisiana University, USA
}

\begin{abstract}
Uncertainty about the economy can increase volatility in financial market returns. One potential source of uncertainty is the outcome of an upcoming national election. This paper uses a GARCH model to estimate the effect of uncertainty surrounding U.S. Presidential elections on the volatility of U.S. stock market returns from 1992-2012. Uncertainty in these elections is measured using asset prices from the Iowa Electronic Market (IEM), an on-line futures market based on real-world events, including U.S. elections. The empirical results show that the conditional variance in $S \& P 500$ returns increases when IEM presidential election futures market asset prices indicate greater uncertainty about the outcome of an upcoming election.
\end{abstract}

Keywords: Stock Market; Election; GARCH; Iowa Electronic Market; Volatility; Efficient Market Hypothesis

\section{INTRODUCTION}

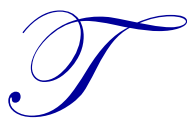

he efficient market hypothesis states that all relevant information and expectation is immediately reflected in stock share prices. Uncertainty about the future course of the economy may make expectations more difficult to incorporate into current prices, creating greater volatility in financial market returns. One potential source of uncertainty is the outcome of an upcoming national election. If different presidential candidates are associated with contrasting regulatory and fiscal policies, then financial market participants may have differing views about the future performance of the economy depending on the eventual winner. Therefore, greater uncertainty about the expected eventual winner in a U.S. presidential election would create greater volatility in markets (Borzykowski, 2016).

In this paper, a Generalized AutoRegressive Conditional Heteroskedasticity (GARCH) model of daily returns for the S\&P 500 Index is used to measure the impacts on stock market volatility of greater uncertainty about the outcome of a U.S. presidential election. The measure of election uncertainty is based on asset prices from the Iowa Electronic Market (IEM). The IEM is a real money online futures market where payoffs are based on real world events, including U.S. presidential elections. This market is an educational and research project operated by the Tippie College of Business at the University of Iowa. While the primary purposes of the IEM are education and research, participants buy and sell assets and realize profits and losses with real money as in any "real world" market. Because real money is involved it has been suggested that asset prices in political futures markets like the IEM may better reflect anticipated election outcomes than polls. (Berg, Nelson, \& Rietz, 2008) The basic premise is that a poll reflects the candidate respondents want to win, but in a real money futures market participants buy and sell political candidate contracts at different prices based on the candidate they really think will win. Therefore, in this study asset prices from the IEM U.S. Presidential election futures markets are used as an alternative to poll data in determining the anticipated "closeness" of an election.

This statistical model will use a unique data set that may provide results comparable to previous studies of the relationship between national election outcomes and financial market returns. The results may also inform the discussion of how uncertainty impacts the incorporation of expectations into market outcomes. In addition, the use of asset prices from a political futures market can demonstrate that activity in these markets is a valuable source of information comparable to poll data in assessing expectations about an election outcome. 


\section{LITERATURE REVIEW}

There has been previous analysis of national elections on stock markets outcomes. Ioannidis and Thompson (1986) used an OLS regression to measure the impact of opinion polls on returns in the London Stock Exchange from 19601979. They find, using monthly observations, that market returns respond positively when polls tip towards more conservative candidates, particularly when polls are closer. Santa-Clara and Volkanov (2003) also used a simple regression to measure excess returns in the stock market under presidencies of the different political parties in the U.S. since 1927. They find that excess returns are higher under Democratic presidents than Republican, but find no difference in the riskiness of the stock market under different administrations.

Regarding political uncertainty and volatility of stock returns, Beaulieu, Cosset, and Essaddam (2005 and 2006) examine the effects of political risks, especially news related to the possible separation of Quebec from Canada, on the volatility of stock returns in Canada. These authors used a GARCH model for stock returns of individual firms in Quebec and find that political risk does impact the volatility of stock returns, particularly for those firms with asset structures and foreign involvement that increase their exposure to political risk. Mattozzi (2008) constructed portfolios of stocks determined to fare well depending on whether George Bush or Al Gore won the U.S. Presidential election in 2000 as a way to hedge election-based risk and found that excess daily returns on these portfolios were significantly influenced by electoral polls during the six months prior to this very close election.

Methodology in this paper is most strongly influenced by Li and Born (2006), who used a GARCH model to estimate the effects of U.S. presidential election uncertainty on volatility in daily stock market returns. Their measure of election uncertainty included dummy variables based on the differences in poll numbers for the two major party candidates from the end of the party conventions up to election day for U.S. presidential elections between 1964 and 2000. Their evidence suggests that closer elections, based on poll numbers, resulted in greater volatility in the daily return of the Center for Research in Security Prices (CRSP) value-weighted index. In addition, they find that average returns in the CRSP are higher during an election period when an election is close but are indistinguishable from mean daily returns during non-election periods if, based on polls, the election was anticipated to be a landslide.

\section{GENERAL MODEL AND HYPOTHESIS}

It is common and generally accepted practice to model stock returns as a Generalized AutoRegressive Conditional Heteroscedasticity (GARCH) model (Beaulieu, et al, 2006; Zivot, 2008; Ahmed \& Suliman, 2011). The basic GARCH model involves estimates of both a conditional mean equation and a conditional variance equation, as shown:

$$
\text { Conditional Mean: } y_{t}=\beta_{i} X_{i}+\varepsilon_{t}
$$

where $\mathrm{X}_{\mathrm{i}}$ will typically include lagged values of the dependent variable but can also include other explanatory variables, and

$$
\text { Conditional Variance: } \sigma_{t}^{2}=\theta_{0}+\alpha_{1} \varepsilon_{t-1}^{2}+\ldots+a_{p} \varepsilon_{t-p}^{2}+\gamma_{1} \sigma_{t-1}^{2}+\ldots+\gamma_{q} \sigma_{t-q}^{2}
$$

where the $\alpha$ terms are referred to as the ARCH terms and the $\gamma$ terms are called GARCH terms. Other terms may enter the conditional variance estimate as a part of the constant term, $\theta_{0}$, and it will be these terms that become the focus of this study as the variance of stock returns is the measure of volatility (Ahmed \& Suliman, 2011).

The specific model estimated in this study, following the example set by Li and Born (2006), is:

$$
\text { Conditional Mean: } r_{t}=\beta_{0}+\beta_{1} r_{t-1}+\beta_{2} U_{t}+\beta_{3} E_{t}+\beta_{4} I_{t}+\varepsilon_{t}
$$

Where $r_{t}$ is the daily return from the S\&P 500 stock index, $U_{t}$ is the measure of U.S. presidential election uncertainty (described in detail below), $\mathrm{E}_{\mathrm{t}}$ is a dummy variable indicating whether day $\mathrm{t}$ is during an election year $\left(\mathrm{E}_{\mathrm{t}}=1\right.$ if an election year, 0 otherwise), and $I_{t}$ is another dummy variable to indicate whether the election includes a viable independent candidate, which may further add to the uncertainty surrounding the election $\left(\mathrm{I}_{t}=1\right.$ if a viable independent candidate is running, 0 otherwise). A viable independent candidate in this case is one who continued to have an asset 
offered for sale in the IEM presidential election markets throughout the election, including after the major party conventions. The only elections in which this was the case were in 1992 and 1996, during which H. Ross Perot garnered sufficient support as an independent candidate to warrant a separate asset traded in the IEM presidential futures markets.

As with many models of stock returns, including Li and Born (2006) and Zivot (2008), this study uses a GARCH $(1,1)$ estimation, meaning there is a single lagged variable in the ARCH and GARCH terms of the conditional variance equation. The election uncertainty variables will be included in the conditional variance equation and will enter as exponential terms along with the constant.

$$
\text { Conditional Variance: } \sigma_{t}^{2}=\exp \left(\theta_{0}+\theta_{1} U_{t}+\theta_{2} E_{t}+\theta_{3} I_{t}\right)+a \varepsilon_{t-1}^{2}+\gamma \sigma_{t-1}^{2}
$$

The specific hypothesis to be tested is:

$\mathbf{H}_{0}: \theta_{1}=0$

Rejecting this null hypothesis would support that argument that uncertainty about U.S. Presidential elections does influence the volatility of stock market returns.

\section{DATA}

The two sources of data used in this model are daily values of the S\&P 500 stock index and daily price data from the IEM. The S\&P 500 was chosen as a broad measure of stock performance that is closely tied to the performance of the U.S. economy and therefore likely to be affected by U.S. political uncertainty. The IEM is chosen as the source of political futures market asset prices because it is well established and has operated consistently over several U.S. Presidential elections.

Data cover daily values on open stock trading days from January 2, 1992 through election day (November $9^{\text {th }}$ ) 2012. Stock market return data is based on closing daily values of the S\&P 500 stock index. Following many studies, including Ahmed and Suliman (2011), the continuously compounded daily return is computed as:

$$
\mathrm{r}_{\mathrm{t}}=\ln \left(\mathrm{SP}_{\mathrm{t}} / \mathrm{SP}_{\mathrm{t}-1}\right)
$$

where $\mathrm{SP}_{\mathrm{t}}$ is the closing daily value of the $\mathrm{S} \& \mathrm{P} 500$ stock index.

Measures of election uncertainty are based on two kinds of futures contracts traded in the IEM. One type of contract is called a "Vote Share" contract. Vote Share contracts for a presidential candidate eventually pay out, as a fraction of $\$ 1.00$, the overall share of the popular vote earned by that candidate in the national election. For example, if a candidate earns $58 \%$ of the popular vote in the election, then market participants will earn $\$ 0.58$ for each contract of that candidate that they hold at the close of the market on election day. The other contract is called a "Winner-Take-All" contract. In the Winner-Take-All market, contracts for the candidate who is declared the winner of the election will pay out $\$ 1.00$, while all other contracts will pay $\$ 0$.

Based on these two types of contracts traded in the IEM the measure of election uncertainty, $\mathrm{U}_{\mathrm{t}}$, will take one of four forms, resulting in four separate model estimations. The first two measures are dummy variables that take on a value of 1 when the difference in price between the Democrat and Republican candidates' contracts in either the Vote Share or Winner-Take-All market is sufficiently large to suggest that the election outcome is relatively certain. This variable follows the use of a dummy variable by $\mathrm{Li}$ and Born (2006) based on the closeness of the major party candidates in polls. The two dummy variables in this study are defined below.

In the Winner-Take-All market, $\mathrm{U}_{\mathrm{t}}=1$ if $/ \mathrm{WTAD}_{\mathrm{t}}-\mathrm{WTAR}_{\mathrm{t}}>=0.44$ ( 0 otherwise $)$, where WTAD $\mathrm{W}_{\mathrm{t}}$ and WTARt represent the closing daily contract price of the Democrat and Republican candidates respectively in the IEM WinnerTake-All market. Absolute values are used because it does not matter which party candidate's contract has a higher price, only how "close" the prices are. A value of 0 would indicate prices of $\$ 0.50$ for each candidate, suggesting that 
the election is a "toss up". Larger differences in the contract prices would indicate less uncertainty about the election outcome. The value of 0.44 represents the mean difference between the Winner-Take-All contract prices between the end of both major party conventions and election day during all elections within the study period.

In the Vote Share market, $\mathrm{U}_{\mathrm{t}}=1$ if $/ \mathrm{VSD}_{\mathrm{t}}-\mathrm{VSR}_{\mathrm{t}} />=0.06$ ( 0 otherwise), where VSD $\mathrm{V}_{\mathrm{t}}$ and VSR $\mathrm{t}$ represent the closing daily contract price of the Democrat and Republican candidates respectively. Again, absolute values are used because it doesn't matter which party candidate's contract has a higher price but only how close the election is expected to be. A value of 0 would indicate prices of $\$ 0.50$ for each candidate, suggesting that IEM participants feel that each candidate will receive no less than $50 \%$ of the popular vote, or the closest possible election. Larger differences in the contract prices would therefore indicate less uncertainty about the election outcome. The value of 0.06 represents the mean difference between the Vote Share contract prices from the end of both major party conventions to election day during all elections within the study period.

The other two measures for $U_{t}$ are simply the absolute difference between the Democrat and Republican candidates' contract prices in the Vote Share or Winner-Take-All markets:

$$
\mathrm{U}_{\mathrm{t}}=/ \mathrm{WTAD}_{\mathrm{t}}-\mathrm{WTAR}_{\mathrm{t}} / \text { or } \mathrm{U}_{\mathrm{t}}=/ \mathrm{VSD}_{\mathrm{t}}-\mathrm{VSR}_{\mathrm{t}} /
$$

Smaller differences in these values would represent greater uncertainty about the outcome of the election. The contract prices can be compared to poll numbers: the closer the prices the closer the election is anticipated. Because these are market asset prices and not poll results, there is no need to account for any margin of error. Again, absolute values are used because the intent is to measure only the closeness of the election, not the party of the favored candidate.

Following Li and Born (2006) the main focus of the study is election uncertainty between the end of the last major party primary and election day. At this time both major party candidates have been officially chosen and the relevant IEM contract prices can be utilized. During non-election periods, that is before the major party conventions have occurred and after the election is over, all of the election uncertainty variables are assigned a value of 1 . During these time periods, it is assumed that there is perfect certainty regarding who is, or will soon be inaugurated as, President of the U.S.

The other explanatory variables are $\mathrm{I}_{\mathrm{t}}$ and $\mathrm{E}_{\mathrm{t}}$. The variable $\mathrm{I}_{\mathrm{t}}$, indicating the inclusion of a viable independent candidate, has been fully described above. Also, as previously described, $E_{t}$ is a dummy variable that indicates days during an election year up until election day. The use of this variable follows the example of the model estimated by Li and Born (2006), which included a dummy variable for days when the polls were officially open and was meant to indicate the notion that "election season is upon us." As an alternative, in this study the comparable dummy variable simply indicates that it is an election year. The assertion is that the turn of calendar year to an election year is a clear signal that an election is on its way. This variable may also capture any uncertainty surrounding party primaries up until the days of the conventions, after which actual IEM contract prices are utilized.

Summary statistics for all variables are presented in table 1. In this table, the variables WTADUM, VSDUM, WTADIFF and VSDIFF represent the four uncertainty measure options $\left(U_{t}\right)$ for dummies in the Winner-Take-All (WTA) and Vote Share (VS) markets, and absolute differences between the major party candidate contract prices for WTA and VS contracts, respectively. 
Table 1. Summary Statistics

\begin{tabular}{l|l|c|c|c|l}
\hline \multicolumn{1}{c}{ Variable } & Mean & Std. Dev. & Min & Max & \multicolumn{1}{c}{ Description } \\
\hline $\mathrm{r}$ & 0.008 & 0.0089 & & 0.1096 & S\&P 500 daily return \\
\hline $\mathrm{E}$ & 0.25 & 0.43 & 0 & 1 & Election year dummy \\
\hline $\mathrm{I}$ & 0.018 & 0.13 & 0 & 1 & Independent candidate dummy \\
\hline WTADUM & 0.97 & 0.17 & 0 & 1 & Winner-Take-All dummy \\
\hline VSDUM & 0.97 & 0.16 & 0 & 1 & Vote Share dummy \\
\hline WTADIFF & 0.97 & 0.14 & 0.027 & $1.022^{1}$ & Winner-Take-All price difference \\
\hline VSDIFF & 0.95 & 0.21 & 0.001 & 1 & Vote Share price difference \\
\hline
\end{tabular}

Observations $=5256$

1 During the 2004 election the Republican candidate Winner-Take-All contract was split into two separate contracts resulting in cases of the total combined contract price adding to $>\$ 1.00$

Because the IEM contract price dummies and differences have been assigned values of 1 during non-election periods, a separate set of summary statistics for these variables only on days during election periods, defined as between the end of both major party conventions and election day, is presented in Table 2.

Table 2. Summary statistics for uncertainty measures during election periods

\begin{tabular}{l|l|l|l|l|l}
\hline \multicolumn{1}{c}{ Variable } & \multicolumn{1}{c}{ Mean } & \multicolumn{1}{c}{ Std. Dev. } & \multicolumn{2}{c}{ Min } & \multicolumn{1}{c}{ Max } \\
\hline WTADUM & 0.43 & 0.496 & 0 & 1 & Description \\
\hline VSDUM & 0.49 & 0.5007 & 0 & 1 & Vinner-Take-All dummy \\
\hline WTADIFF & 0.44 & 0.29 & 0.027 & $1.022^{1}$ & Winner-Take-All price difference \\
\hline VSDIFF & 0.0605 & 0.042 & .001 & 0.277 & Vote Share price difference \\
\hline
\end{tabular}

Observations $=284$

1 During the 2004 election the Republican candidate Winner-Take-All contract was split into two separate contracts resulting in cases of the total combined contract price adding to $>\$ 1.00$

\section{EMPIRICAL RESULTS AND CONCLUSIONS}

Four separate estimations of the GARCH model specified by equations (3) and (4) are presented using the different measures of election uncertainty, $U_{t}$. Table 3 presents the results using the dummy variables (WTADUM and VSDUM) as the election uncertainty measure, while Table 4 presents the estimates with the IEM contract price difference measures (WTADIFF and VSDIFF). As with other models of stock returns, including Li and Born (2006) and Ferenstein and Gasowski (2004), this model assumes a student's t-distribution for the error term.

Results for both estimates using IEM price dummies are presented in Table 3. The negative and statistically significant estimated coefficients for both the Winner-Take-All and Vote Share market dummies in the conditional variance equation reject the null hypothesis and support the argument that greater uncertainty surrounding U.S. Presidential elections creates greater volatility in stock returns. Because these variables take on the value of 1 when the price difference between candidates is sufficiently large, signifying greater certainty in the election outcome, the negative coefficient indicates greater variance in returns during closer elections. This result is consistent with the findings of $\mathrm{Li}$ and Born (2006) who used similar dummy variables based on election period polls.

The estimated coefficient on $\mathrm{I}_{\mathrm{t}}$, indicating the presence of a major independent candidate participating in the election, is consistently positive in the conditional mean equation. This result indicates that market returns are higher on average when a viable third candidate is participating in the election. However, it is possible that because the elections that included the viable third candidate in this study period both occurred in the early to mid1990's, this variable is acting as a "1990's dummy" and is simply capturing the rapid rise in stock markets that began in 1992 and persisted until late in that decade.

Similar results are obtained when actual price differences between candidate contracts in the IEM are used as the uncertainty measure. As shown in Table 4, both the WTADIFF and VSDIFF variables have coefficients that are negative and statistically significant. Again, since smaller values for this variable are an indication of greater election uncertainty, the negative coefficient suggests a greater variance in stock returns during "closer" elections. 
Table 3. GARCH results with item price dummies

\begin{tabular}{|c|c|c|c|c|c|c|c|}
\hline \multicolumn{4}{|c|}{ U = WTADUM } & \multicolumn{4}{|c|}{$\mathbf{U}=\mathbf{V S D U M}$} \\
\hline \multicolumn{2}{|c|}{$\begin{array}{l}\text { Observations }=5256 \\
\text { Log Likelihood }=17121.05\end{array}$} & \multicolumn{2}{|c|}{$\begin{array}{l}\text { Wald } \mathrm{chi}^{2}=10.20 \\
\text { Prob }>\text { chi }^{2}=0.0371\end{array}$} & \multicolumn{2}{|c|}{$\begin{array}{l}\text { Observations }=5256 \\
\text { Log Likelihood }=17122.57\end{array}$} & \multicolumn{2}{|c|}{$\begin{array}{l}\text { Wald } \mathrm{chi}^{2}=13.75 \\
\text { Prob }>\mathrm{chi}^{2}=0.0081\end{array}$} \\
\hline \multicolumn{8}{|c|}{ Dependent Variable $=r_{t}($ symmetric $)$} \\
\hline Variable & Coc & icient & $\mathbf{Z}$ & Variable & Coe & icient & $\mathbf{Z}$ \\
\hline \multicolumn{4}{|c|}{ Conditional Mean } & \multicolumn{4}{|c|}{ Conditional Mean } \\
\hline Constant & \multicolumn{2}{|c|}{-0.000059} & -0.08 & Constant & \multicolumn{2}{|c|}{-0.00081} & -1.11 \\
\hline $\mathrm{r}_{\mathrm{t}-1}$ & \multicolumn{2}{|c|}{-0.028} & $1.90^{*}$ & $\mathrm{r}_{\mathrm{t}-1}$ & \multicolumn{2}{|c|}{-0.029} & $-1.92^{*}$ \\
\hline WTADUM & \multicolumn{2}{|c|}{0.00078} & 1.14 & VSDUM & \multicolumn{2}{|c|}{0.0015} & $2.14^{* *}$ \\
\hline $\mathrm{E}$ & \multicolumn{2}{|c|}{-0.00046} & $1.68^{*}$ & $\mathrm{E}$ & \multicolumn{2}{|c|}{-0.00042} & -1.54 \\
\hline I & \multicolumn{2}{|c|}{0.0013} & $1.95^{*}$ & I & \multicolumn{2}{|c|}{0.0014} & $2.08^{* *}$ \\
\hline \multicolumn{4}{|c|}{ Conditional Variance } & \multicolumn{4}{|c|}{ Conditional Variance } \\
\hline Constant & \multicolumn{2}{|c|}{-12.72} & $-20.55^{* *}$ & Constant & \multicolumn{2}{|c|}{-12.6} & $-20.83^{* *}$ \\
\hline WTADUM & \multicolumn{2}{|c|}{-1.54} & $-2.47^{* *}$ & VSDUM & \multicolumn{2}{|c|}{-1.66} & $-2.71^{* *}$ \\
\hline $\mathrm{E}$ & \multicolumn{2}{|c|}{0.082} & 0.20 & $\mathrm{E}$ & \multicolumn{2}{|c|}{0.107} & 0.27 \\
\hline I & \multicolumn{2}{|c|}{-0.77} & -0.74 & I & \multicolumn{2}{|c|}{-0.83} & -0.79 \\
\hline$\varepsilon^{2} \mathrm{t}-1(\mathrm{ARCH})$ & \multicolumn{2}{|c|}{0.073} & $10.33^{* *}$ & $\varepsilon_{\mathrm{t}-1}^{2}(\mathrm{ARCH})$ & \multicolumn{2}{|c|}{0.073} & $10.34^{* *}$ \\
\hline$\sigma_{\mathrm{t}-1}^{2}(\mathrm{GARCH})$ & \multicolumn{2}{|c|}{0.92} & $133.42^{* *}$ & $\sigma_{t-1}^{2}(\mathrm{GARCH})$ & \multicolumn{2}{|c|}{0.92} & $133.51^{* *}$ \\
\hline
\end{tabular}

** Significant at the $5 \%$ confidence level

* Significant at the $10 \%$ confidence level

Neither of the other dummy variables, $E_{t}$ or $\mathrm{I}_{\mathrm{t}}$, show significant results in the conditional variance estimates, however both variable offer consistent results in the conditional mean estimates. The variable indicating an election year, $\mathrm{E}_{\mathrm{t}}$, has negative coefficient, suggesting lower average market returns during election years. Empirical results and opinions have varied about the performance of stock markets during election years. Li and Born (2006) found that mean returns were higher in election periods, but only when polls indicated closer elections. Other researchers however, suggest that markets tend to be weaker during election years, particularly when there is no incumbent (Watts, 2015), or that even though election years may have higher returns than average it is the year before an election year is when stock returns are highest (Holmes, 2015).

This research addresses the question of whether uncertainty in a national election can impact financial markets.

Using prices from a political futures market like the IEM as a measure of election uncertainty in a standard GARCH model of S\&P 500 index returns provides evidence that financial market volatility increases when the outcome of a national election is less certain. These results are consistent with previous research, including Li and Born (2006), and provides additional support for the assertion of a direct connection between political outcomes and uncertainty about the economy. Whether the same results would be found using other U.S. or even international financial market indices is a matter of empirical investigation. Given that returns for different market indices have been found to be highly correlated, particularly in recent decades (Quinn \& Voth, 2008), it seems likely that similar effects could be found. 
Table 4. GARCH results with IEM price differences

\begin{tabular}{|c|c|c|c|c|c|c|c|}
\hline \multicolumn{4}{|c|}{ U = WTADIFF } & \multicolumn{4}{|c|}{$\mathbf{U}=$ VSDIFF } \\
\hline \multicolumn{2}{|c|}{$\begin{array}{l}\text { Observations }=5256 \\
\text { Log Likelihood }=17120.59\end{array}$} & \multicolumn{2}{|c|}{$\begin{array}{l}\text { Wald } \mathrm{chi}^{2}=10.26 \\
\text { Prob }>\text { chi }^{2}=0.0363\end{array}$} & \multicolumn{2}{|c|}{$\begin{array}{l}\text { Observations }=5256 \\
\text { Log Likelihood }=17119.94\end{array}$} & \multicolumn{2}{|c|}{$\begin{array}{l}\text { Wald } \mathrm{chi}^{2}=9.52 \\
\text { Prob }>\text { chi }^{2}=0.0494\end{array}$} \\
\hline \multicolumn{8}{|c|}{ Dependent Variable $=r_{t}($ symmetric $)$} \\
\hline Variable & Co & cient & $\mathbf{Z}$ & Variable & Co & icient & $\mathbf{Z}$ \\
\hline \multicolumn{4}{|c|}{ Conditional Mean } & \multicolumn{4}{|c|}{ Conditional Mean } \\
\hline Constant & & 033 & -0.08 & Constant & & 0013 & 0.18 \\
\hline$r_{t-1}$ & & & $1.90^{*}$ & $\mathrm{r}_{\mathrm{t}-1}$ & & 28 & $-1.90^{*}$ \\
\hline WTADIFF & & 106 & 1.14. & VSDIFF & & 0059 & 0.80 \\
\hline E & & 045 & $1.68^{*}$ & $\mathrm{E}$ & & 0046 & $-1.65^{*}$ \\
\hline I & & & $1.95^{*}$ & I & & 016 & $1.86^{*}$ \\
\hline \multicolumn{4}{|c|}{ Conditional Variance } & \multicolumn{4}{|c|}{ Conditional Variance } \\
\hline Constant & \multicolumn{2}{|c|}{-12.51} & $-20.55^{* *}$ & Constant & \multicolumn{2}{|c|}{-13.0082} & $-20.22^{* *}$ \\
\hline WTADIFF & \multicolumn{2}{|c|}{-1.76} & $-2.47^{* *}$ & VSDIFF & \multicolumn{2}{|c|}{-1.26} & $-1.97^{* *}$ \\
\hline $\mathrm{E}$ & \multicolumn{2}{|c|}{0.109} & 0.20 & $\mathrm{E}$ & \multicolumn{2}{|c|}{0.16} & 0.42 \\
\hline I & \multicolumn{2}{|c|}{-0.96} & -0.74 & I & \multicolumn{2}{|c|}{-1.75} & -1.16 \\
\hline$\varepsilon^{2} \mathrm{t}-1(\mathrm{ARCH})$ & \multicolumn{2}{|c|}{0.073} & $10.33^{* *}$ & $\varepsilon_{\mathrm{t}-1}^{2}(\mathrm{ARCH})$ & \multicolumn{2}{|c|}{0.073} & $10.33^{* *}$ \\
\hline$\sigma_{t-1}^{2}(\mathrm{GARCH})$ & \multicolumn{2}{|c|}{0.92} & $133.42^{* *}$ & $\sigma_{t-1}^{2}(\mathrm{GARCH})$ & \multicolumn{2}{|c|}{0.92} & $133.61^{* *}$ \\
\hline
\end{tabular}

** Significant at the $5 \%$ confidence level

* Significant at the $10 \%$ confidence level

The results also provide support for the argument that greater uncertainty can increase market volatility that is not incompatible with an efficient market hypothesis. While critics of the efficient market hypothesis have pointed to excessive volatility as evidence against market efficiency (Cochrane, 1991), this research supports the argument that greater volatility does result when relevant and publicly available information becomes less certain (Kostohryz, 2011) and is consistent with market efficiency. In this case, the result is shown to be true when the information relates to a broadly followed and widely influential outcome, such as a national election.

Finally, this research also illustrates the usefulness of data from political futures markets like the IEM. The value of information from these kinds of markets has been criticized based on market participants being biased and not a representative sample of the population (Forsythe, Nelson, \& Neumann, 1992; Berg \& Reitz, 2006). However, statistical results presented here are consistent with previous research results that used more conventional data sources, namely election polls, suggesting that price data from a political futures market like the IEM can be a valuable source of information that should not be overlooked.

\section{AUTHOR BIOGRAPHY}

David Bowes is an Associate Professor of Economics at Southeastern Louisiana University. He has his Ph.D. in Economics from Georgia State University with concentrations in Urban and Environmental Economics. He has been teaching economics for 15 years and has also worked as a research consultant in regional development. His research interests include economics pedagogy, urban growth issues, environmental policy, and financial markets. Email: dbowes@selu.edu

\section{REFERENCES}

Ahmed, A. E. M. A. \& S. Z. Suliman (2011). Modeling stock market volatility using GARCH models evidence from Sudan. International Journal of Business and Social Science, 2(23), 114-28.

Beaulieu, M., J. Cosset, \& N. Essaddam (2006). Political uncertainty and stock market returns: evidence from the 1995 Quebec referendum. The Canadian Journal of Economics, 39(2), 621-641.

Beaulieu, M., J. Cosset, \& N. Essaddam (2005). The impact of political risk on the volatility of stock returns: The case of Canada. Journal of International Business Studies, 36(6), 701-718.

Berg, J. E., F. D. Nelson, \& T. A. Rietz (2006). The Iowa electronic markets: Stylized facts and open issues. In Information Markets: A New Way of Making Decisions. R. Hahn \& P. Tetlock, ed. AEI/Brookings Center for Regulatory Studies, 142-169. 
Berg, J. E., F. D. Nelson, \& T. A. Rietz (2008). Prediction market accuracy in the long run. International Journal of Forecasting, 24(2), 283-98.

Borzykowski, B. on CNBC.com (2016) Why markets tend to fall during a presidential election year. CNBC QUARTERLY INVESTMENT GUIDE, http://www.cnbc.com/2016/01/13/why-markets-tend-to-fall-during-a-presidential-electionyear.html.

Cochrane, J. H. (1991). Volatility tests and efficient markets: A review essay. Journal of Monetary Economics, 27, 463-485.

Ferenstein, E. \& M. Gasowski (2004). Modelling stock returns with AR-GARCH processes. SORT 28 (1), 55-68.

Forsythe, R., F. D. Nelson, G. R. Neumann \& J. Wright (1992). Anatomy of an experimental political stock market. American Economic Review, 82(5), 1142-1161.

Holms, F. on Forbes.com (2015). Years before presidential elections usually big winners for stocks. http://www.forbes.com/sites/greatspeculations/2015/08/14/years-before-presidential-elections-usually-big-winners-forstocks/\#2ccd41fd269e.

Ioannidis, C. \& R. S. Thompson (1986). Political opinion polls and the stock market. Managerial and Decision Economics, 7(4), 267-271.

Kostohry, J.A. (2011). Wild volatility ironically validates efficient market hypothesis. https://seekingalpha.com/article/292012wild-volatility-ironically-validates-efficient-market-hypothesis.

Li, J. \& J. A. Born (2006). Presidential election uncertainty and common stock returns in the United States. The Journal of Financial Research, 29(4), 609-22.

Mattozzi, A. (2008). Can we insure against political uncertainty? Evidence from the U.S. stock market. Public Choice, 137, 4355.

Quinn, D.P. \& H. Voth (2008). A century of global equity market correlations. American Economic Review: Papers \& Proceedings, 98(2), 535-540.

Santa-Clara, P. \& R. Valkanov (2003). The presidential puzzle: political cycles and the stock market, The Journal of Finance, 58(5), 1841-1872.

Watts, W. in MarketWatch (2015). 2016 predictions: What presidential election years mean for stocks. http://www.marketwatch.com/story/2016-predictions-what-presidential-election-years-mean-for-stocks-2015-12-29.

Zivot, E. (2008). Practical issues in the analysis of univariate GARCH models. http://faculty.washington.edu/ezivot/research/practicalgarchfinal.pdf. 